ARTICLE

https://doi.org/10.1038/s41467-020-20861-2

\title{
A safety cap protects hydrogenase from oxygen attack
}

Martin Winkler ${ }^{1,7}$, Jifu Duan (1) 1,7, Andreas Rutz ${ }^{1}$, Christina Felbek (10 2, Lisa Scholtysek', Oliver Lampret ${ }^{1}$, Jan Jaenecke1, Ulf-Peter Apfel ${ }^{3,4}$, Gianfranco Gilardi (1) ${ }^{5}$, Francesca Valetti (i) ${ }^{5}$, Vincent Fourmond (10) ${ }^{2}$, Eckhard Hofmann (iD) ${ }^{6}$, Christophe Léger (i) ${ }^{2 \otimes} \&$ Thomas Happe (i) ${ }^{1 凶}$

[FeFe]-hydrogenases are efficient $\mathrm{H}_{2}$-catalysts, yet upon contact with dioxygen their catalytic cofactor (H-cluster) is irreversibly inactivated. Here, we combine X-ray crystallography, rational protein design, direct electrochemistry, and Fourier-transform infrared spectroscopy to describe a protein morphing mechanism that controls the reversible transition between the catalytic $\mathrm{H}_{\mathrm{ox}}$-state and the inactive but oxygen-resistant $\mathrm{H}_{\text {inact }}$-state in [FeFe]-hydrogenase $\mathrm{CbA} 5 \mathrm{H}$ of Clostridium beijerinckii. The $\mathrm{X}$-ray structure of air-exposed $\mathrm{CbA} 5 \mathrm{H}$ reveals that a conserved cysteine residue in the local environment of the active site (H-cluster) directly coordinates the substrate-binding site, providing a safety cap that prevents $\mathrm{O}_{2}$-binding and consequently, cofactor degradation. This protection mechanism depends on three nonconserved amino acids situated approximately $13 \AA$ away from the $\mathrm{H}$-cluster, demonstrating that the 1st coordination sphere chemistry of the $\mathrm{H}$-cluster can be remote-controlled by distant residues.

\footnotetext{
${ }^{1}$ Photobiotechnology, Department of Plant Biochemistry, Ruhr-Universität Bochum, 44801 Bochum, Germany. ${ }^{2}$ CNRS, Aix-Marseille Université, Laboratoire de Bioénergétique et Ingénierie des Protéines, Institut de Microbiologie de la Méditerranée, Marseille, France. ${ }^{3}$ Inorganic Chemistry I, Department of Chemistry and Biochemistry, Ruhr-Universität Bochum, 44801 Bochum, Germany. ${ }^{4}$ Fraunhofer UMSICHT, 46047 Oberhausen, Germany. ${ }^{5}$ Department of Life Sciences and Systems Biology, University of Torino, Torino 10123, Italy. ${ }^{6}$ Protein Crystallography, Department of Biophysics, Ruhr-Universität Bochum, 44801 Bochum, Germany. ${ }^{7}$ These authors contributed equally: Martin Winkler, Jifu Duan. ${ }^{凶}$ email: christophe.leger@imm.cnrs.fr; thomas.happe@rub.de
} 


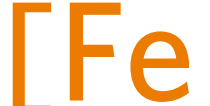

Fe]-hydrogenases catalyze the reversible reduction of protons to dihydrogen at low overpotential and high turnover rates ${ }^{1-3}$. Their catalytic cofactor consists of a $[4 \mathrm{Fe}-4 \mathrm{~S}]$-cluster $\left([4 \mathrm{Fe}]_{\mathrm{H}}\right)$ that is covalently bound to a diiron complex $\left([2 \mathrm{Fe}]_{\mathrm{H}}\right)$ by a bridging cysteine ${ }^{4}$. The two Fe-sites of the $[2 \mathrm{Fe}]_{\mathrm{H}}$ complex, referred to as proximal $\left(\mathrm{Fe}_{\mathrm{p}}\right)$ and distal $\left(\mathrm{Fe}_{\mathrm{d}}\right)$ according to their distance to the $[4 \mathrm{Fe}]_{\mathrm{H}^{-}}$-cluster, are coordinated by three carbon monoxide $(\mathrm{CO})$ and two cyanide $\left(\mathrm{CN}^{-}\right)$ligands ${ }^{1}$. They exhibit strong vibrational absorption signals at discrete infrared frequencies, which respond to changes in redox and protonation states of the H-cluster ${ }^{5-7}$. The diatomic ligands are responsible for the low-spin state of the $[2 \mathrm{Fe}]_{\mathrm{H}}$ sub-cluster and stabilize it in a configuration that creates an open coordination site at $\mathrm{Fe}_{\mathrm{d}}$, allowing the binding and heterolytic splitting of dihydrogen ${ }^{8,9}$. The open coordination site at $\mathrm{Fe}_{\mathrm{d}}$ is also the major target of inhibitors such as $\mathrm{CO}$ and dioxygen ${ }^{10-14}$. The pending bridgehead amine-group of the azadithiolate-ligand which connects $\mathrm{Fe}_{\mathrm{p}}$ and $\mathrm{Fe}_{\mathrm{d}}$ in the $[2 \mathrm{Fe}]_{\mathrm{H}^{-}}$ cluster shuttles protons between $\mathrm{Fe}_{\mathrm{d}}$ and a nearby located cysteine residue $(\mathrm{C} 367$ in $\mathrm{CbA} 5 \mathrm{H})$, which is part of the highly conserved proton transfer pathway ${ }^{4,6,15-18}$.

Dioxygen irreversibly damages the $\mathrm{H}$-cluster of most [FeFe]hydrogenases ${ }^{10-12,14}$. After reaching the active center by diffusion via packing defects ${ }^{11,19-21}, \mathrm{O}_{2}$ binds to the open coordination site at $\mathrm{Fe}_{\mathrm{d}}$, forming a transient adduct which is further transformed by successive protonation and reduction steps ${ }^{11,14,22,23}$. To a limited extent it can be fully reduced to water, partial reduction and protonation however, lead to the production of reactive oxygen species (ROS) that cause H-cluster destruction ${ }^{11,12,22-26}$. To the best of our knowledge, among the [FeFe]-hydrogenases that have been characterized so far, only the recently isolated $\mathrm{CbA} 5 \mathrm{H}$ of Clostridium beijerinckii, a gram-positive, anaerobic bacterium isolated from soil and feces, has been shown to resist long-term exposure to $\mathrm{O}_{2}$, by reversibly switching from the active oxidized ready state $\mathrm{H}_{\mathrm{ox}}$ to the $\mathrm{O}_{2}$-protected but inactive $\mathrm{H}$ cluster state $\mathrm{H}_{\text {inact }}{ }^{27}$. This could be demonstrated by monitoring the spectroscopic signature of the enzyme that is repeatedly oxidized in air and reduced by $\mathrm{H}_{2}$ (ref. ${ }^{27}$ and Supplementary Figure 1). The $\mathrm{H}_{\text {inact-state }}$ was originally identified as the 'as isolated' form of [FeFe]-hydrogenase DdH from Desulfovibrio desulfuricans after homologous expression and aerobic purification ${ }^{28,29} \cdot \mathrm{H}_{\text {inact }}$ provides full protection against $\mathrm{O}_{2}$ prior to the first reductive activation to $\mathrm{H}_{\mathrm{ox}}$ and can be identified spectroscopically by a characteristic set of IR-signals. However, DdH becomes $\mathrm{O}_{2}$-sensitive after gaining catalytic activity ${ }^{10,19}$. For $\mathrm{DdH}$ and some other [FeFe]-hydrogenases, sulfide-addition under oxidizing conditions (either aerobic or anaerobic) also

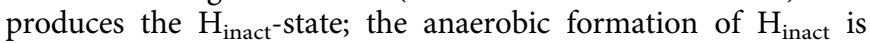
detected in cyclic voltammetry by the early onset of oxidative inactivation ${ }^{30,31}$. Rodríguez-Maciá et al. concluded that $\mathrm{H}_{\text {inact }}{ }^{-}$ formation under oxidizing conditions is the consequence of sulfide-binding to $\mathrm{Fe}_{\mathrm{d}}{ }^{30}$, but this protected state is also formed in $\mathrm{CbA}_{5} \mathrm{H}^{27,31}$ and CpIII ([FeFe]-hydrogenase III from Clostridium pasteurianum $)^{32}$ in the absence of exogenous sulfide. The sulfideindependent, reversible transition between $\mathrm{H}_{\mathrm{ox}}$ and the inactive, $\mathrm{O}_{2}$-resistant $\mathrm{H}_{\text {inact }}$-state is therefore an uncharacterized and intriguing feature of certain [FeFe]-hydrogenases, which significantly enhances their utilization potential (Fig. 1; CbA5H).

In this work, we elucidate the mechanism that protects $\mathrm{CbA} 5 \mathrm{H}$ from dioxygen employing a multidisciplinary approach. We describe the structural rearrangement of a polypeptide-loop close to the active site that attributes a 'safety cap' function to the conserved cysteine at position 367. It shields the open coordination site of $\mathrm{Fe}_{\mathrm{d}}$ from $\mathrm{O}_{2}$ by enabling the thiol-group to reversibly bind to $\mathrm{Fe}_{\mathrm{d}}$, thus providing an intrinsic source for the protective sulfide-ligand.

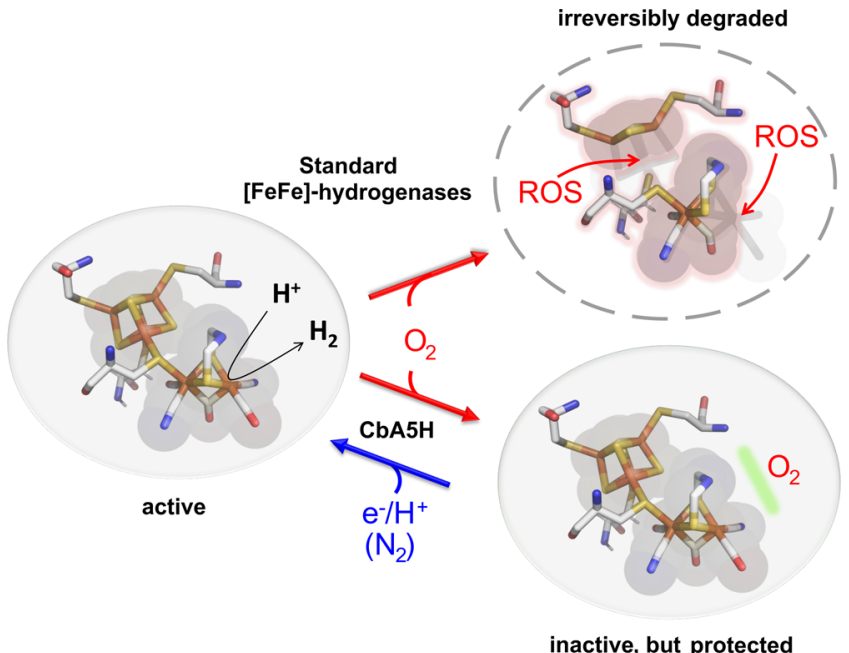

Fig. 1 The unusual $\mathrm{O}_{2}$-resistance of [FeFe]-hydrogenase $\mathbf{C b A 5 H}$. The $\mathrm{H}$ cluster of $\mathrm{Cpl}$ and other [FeFe]-hydrogenases is irreversibly destroyed when exposed to $\mathrm{O}_{2}$. $\mathrm{CbA} 5 \mathrm{H}$ is a rare exception, as it reversibly converted into an inactive but $\mathrm{O}_{2}$-protected state $\left(\mathrm{H}_{\text {inact }}\right)$, even in the absence of exogenous sulfide. From the $\mathrm{O}_{2}$-protected state, $\mathrm{CbA} 5 \mathrm{H}$ can be reactivated by reduction under anaerobic conditions. ROS: reactive $\mathrm{O}_{2}$-species resulting from $\mathrm{O}_{2}$-activation after $\mathrm{Fe}_{\mathrm{d}}$-binding. Green bar: unknown feature or mechanism, protecting the $\mathrm{H}$-cluster of $\mathrm{CbA5H}$ from $\mathrm{O}_{2}$-attack in $\mathrm{H}_{\text {inact }}$.

\section{Results}

Crystal structure of $\mathrm{O}_{2}$-exposed $\mathrm{CbA5H} \mathbf{H}^{\mathrm{WT}}$. To uncover the structure of the $\mathrm{O}_{2}$-protected enzyme state, we crystallized wildtype $\mathrm{CbA} 5 \mathrm{H}\left(\mathrm{CbA} 5 \mathrm{H}^{\mathrm{WT}}\right)$ under aerobic conditions $\left(\mathrm{CbA} 5 \mathrm{H}^{\text {air }}\right)$ (for details on the crystal and overall structural features see Supplementary Discussion 1, Supplementary Figs. 2-5 and Supplementary Tables 1,2). The overall structure of the H-cluster domain of $\mathrm{CbA} 5 \mathrm{H}^{\text {air }}$ is similar to that of standard [FeFe]hydrogenases like $\mathrm{CpI}$ and $\mathrm{DdH}^{4,33}$. Interestingly, it embeds the H-cluster with nearly full occupancy $(>90 \%)$ (Supplementary Table 2); this stability of the active site in the air-exposed crystal contrasts with the observation that the $\mathrm{H}$-cluster of standard $[\mathrm{FeFe}]$-hydrogenases is destroyed under air ${ }^{26}$. Since we could not crystallize $\mathrm{CbA} 5 \mathrm{H}$ under anaerobic conditions, we compared the structures of $\mathrm{CbA} 5 \mathrm{H}^{\text {air }}$ and $\mathrm{CpI}$, a "standard" [FeFe]-hydrogenase. The structure of $\mathrm{CbA} 5 \mathrm{H}^{\text {air }}$ shows localized structural differences with anaerobically purified CpI (PDB ID: 4XDC) ${ }^{9}$ (Supplementary Figure 3). The peptide-loop that spans T365, S366, and C367 in CbA5H (hereafter "TSC-loop", corresponding to T297, S298, and C299 in CpI) is shifted from the conformation observed in the structures of CpI, DdH, or HydAl (Fig. 2e and Supplementary Figure 5). The bulky side chain of the strictly conserved tryptophan 371 (W303 in CpI), adjacent to the TSCloop, exhibits a different conformation in $\mathrm{CbA} 5 \mathrm{H}^{\text {air }}$, hinging away from the loop. The alpha helix carrying this residue is slightly shifted away from the $\mathrm{H}$-cluster. Consequently, the orientation of the residue of the conserved cysteine C367 in $\mathrm{CbA} 5 \mathrm{H}^{\text {air }}$ is different from that of the corresponding side chain in standard [FeFe]-hydrogenases (Fig. 2d, e and Supplementary Figs. 3 and 5). This observation is consistent with a recently published hypothesis according to which the loop that bears C367 in $\mathrm{CbA} 5 \mathrm{H}$ may be flexible enough to allow the binding of the cysteine to $\mathrm{Fe}_{\mathrm{d}}{ }^{31}$. The strictly conserved cysteine residue is involved in long-range proton transfer to and from the H-cluster (Supplementary Figure 6$)^{4,16,18}$. In $\mathrm{CbA} 5 \mathrm{H}^{\text {air }}$, the distance between the sulfur atom of $\mathrm{C} 367$ and $\mathrm{Fe}_{\mathrm{d}}$ is only $3.1 \AA$, compared to $5.9 \AA$ in CpI (Fig. $2 \mathrm{e})^{9}$ indicating bond-formation. The length of this $\mathrm{C} 367-\mathrm{Fe}_{\mathrm{d}}$ bond is longer than the average length of $2.4 \AA$ 


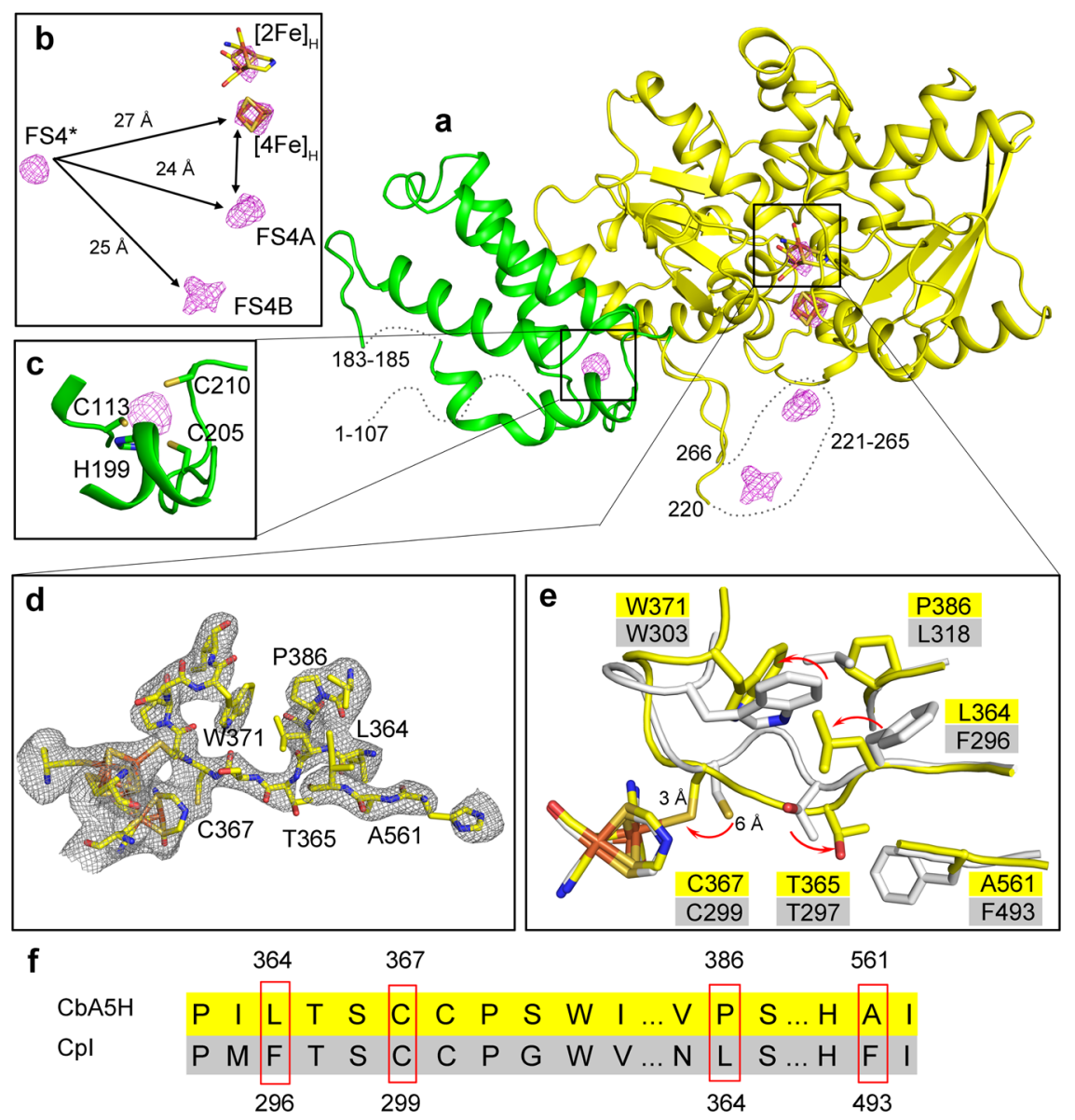

Fig. 2 X-ray structure of CbA5H ${ }^{\mathbf{W T}}$ crystallized under aerobic conditions (CbA5Hair). a Cartoon structure of CbA5H ${ }^{\text {air }}$ (PDB ID: 6TTL, chain A; see Supplementary Figure 2 for the homodimer). $\mathrm{H}$ - and $\mathrm{F}$-domain are colored in yellow, the $\mathrm{N}$-terminal SLBB domain (soluble ligand binding $\beta$-grasp) ${ }^{51}$ is presented in green. $\mathbf{b}$ Anomalous electron density map, depicting the positions and distances between iron-sulfur clusters, including the $\mathrm{H}$-cluster (stick model), the two F-clusters (FS4A and FS4B) and the additional N-terminal cluster within the SLBB domain (FS4*) located more than $20 \AA$ away from any other cluster. c Potential cluster coordination site within the SLBB domain, consisting of 3 cysteine and one histidine ligand. $\mathbf{d}$, e CbA5Hair exhibits a

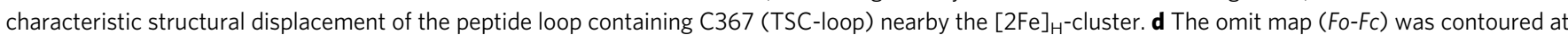
$2 \sigma$ (see Supplementary Fig. 17 for a more detailed structural comparison between the loop regions of $\mathrm{Cpl}$ and $\mathrm{CbA} 5 \mathrm{H}^{\mathrm{air}}$ ). e Structural alignment, depicting conformational differences between $\mathrm{CbA} 5 \mathrm{H}^{\text {air }}$ (yellow) and $\mathrm{Cpl}$ (white). Panels $\mathbf{d}$ and $\mathbf{e}$ focus on the $[2 \mathrm{Fe}]_{\mathrm{H}^{-}}$cluster and side chains of amino acids which influence anaerobic inactivation, $\mathrm{O}_{2}$-resistance, and $\mathrm{H}_{\text {inact }}$ formation. $\mathbf{f}$ Selected parts of an amino acid sequence alignment of $\mathrm{CbA}_{5} \mathrm{HWT}^{\mathrm{W}}$ and $\mathrm{Cpl}$, including the polypeptide positions that influence TSC-loop reconfiguration and $\mathrm{H}_{\text {inact }}$ state formation in $\mathrm{CbA5H}$ WT.

for a covalent bond between iron and $\operatorname{sulfur}^{34}$, but short enough to prohibit the insertion of any molecule (including $\mathrm{H}_{2}$ and $\mathrm{O}_{2}$ ) between the sulfur atom and $\mathrm{Fe}_{\mathrm{d}}$. This observation suggests that the structure of $\mathrm{CbA} 5 \mathrm{H}^{\text {air }}$ is that of an inactive state and explains why the $\mathrm{H}$-cluster is stable under air. That the infrared spectrum of air-exposed CbA5H $\mathrm{H}^{\mathrm{WT}}$ (Fig. 3c and Supplementary Figure 1) shows the typical signature of the $\mathrm{H}_{\text {inact }}$ state suggests that the $\mathrm{X}$ ray structure of $\mathrm{CbA} 5 \mathrm{H}^{\text {air }}$, with $\mathrm{C} 367$ attached to $\mathrm{Fe}_{\mathrm{d}}$, is actually that of $\mathrm{H}_{\text {inact }}$.

The crucial role of $\mathbf{C} 367$ for $\mathbf{H}_{\text {inact }}$-state formation. We compared the properties of $\mathrm{CbA} 5 \mathrm{H}^{\mathrm{WT}}$ and two site-directed variants in which C367 is replaced with either aspartate or alanine. Below, we demonstrate that each of the three distinctive properties of $\mathrm{CbA} 5 \mathrm{H}$ is dependent on the presence of a cysteine at position 367: (1) the non-standard anaerobic oxidative inactivation which occurs at low oxidative potential, (2) the resistance to $\mathrm{O}_{2}$ that results from this inactivation, and (3) the reversible formation of

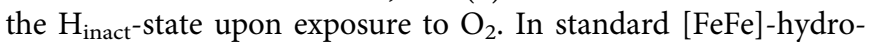
genases, the replacement of the conserved cysteine in the proton transfer pathway with aspartate is the only substitution that preserves a significant level of enzyme activity ${ }^{16,18}$. Consistent with previous results with $\mathrm{CpI}$ and $\mathrm{HydA} 1$, we observed that replacing $\mathrm{C} 367$ with alanine renders $\mathrm{CbA} 5 \mathrm{H}$ inactive while variant $\mathrm{C} 367 \mathrm{D}$ retains $20 \%$ of the $\mathrm{H}_{2}$-production activity measured for $\mathrm{CbA} 5 \mathrm{H}^{\mathrm{WT}}$ and exhibits a shifted $\mathrm{pH}$-optimum (Supplementary Figure 7) ${ }^{18}$.

$\mathrm{H}_{\text {inact }}$ can be accumulated anaerobically by incubating CbA5H $\mathrm{H}^{\mathrm{WT}}$ with oxidants (DCIP or thionine) ${ }^{27}$. Such oxidative treatment can be mimicked in protein film electrochemistry (PFE) experiments by applying high enough electrode potentials ${ }^{35,36}$. The voltammetric response of $\mathrm{CbA5} \mathrm{H}^{\mathrm{WT}}$ (black curve in Fig. 3a, d) resembles that of CPIII ${ }^{32}$ and markedly differs from that of all other characterized $[\mathrm{FeFe}]$-hydrogenases ${ }^{37}$. As expected, a negative current is seen at electrode potentials lower than the Nernst potential of the $\mathrm{H}^{+} / \mathrm{H}_{2}$ redox couple ${ }^{38}$, which reveals proton reduction under reductive conditions. Upon increasing the electrode potential, the current becomes positive, but in contrast to other [FeFe]-hydrogenases, the current strongly decreases above $-0.3 \mathrm{~V}$ vs SHE (standard hydrogen electrode, all potentials refer to $\mathrm{SHE}$ ) as a result of anaerobic, oxidative 

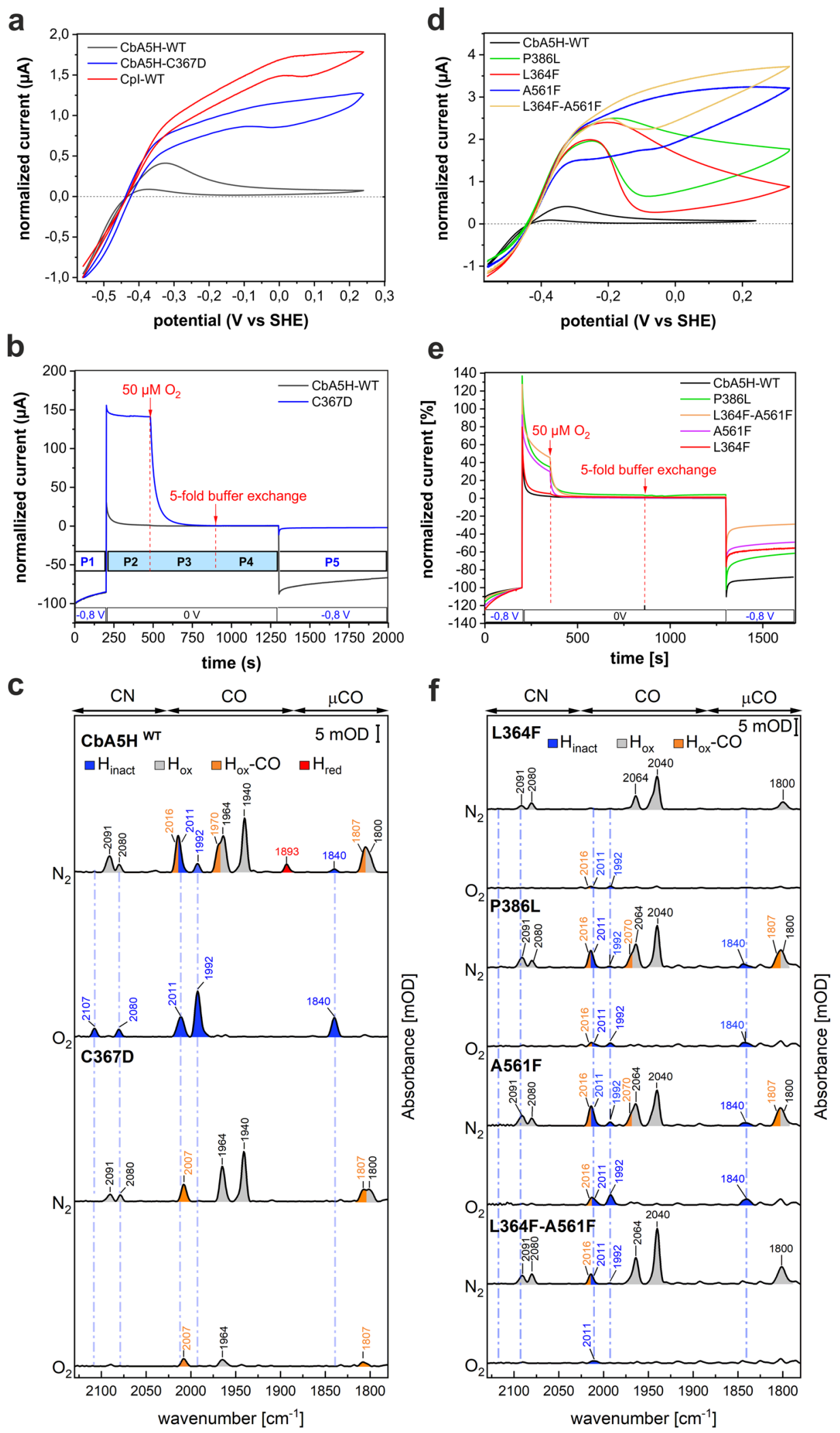

inactivation, as recently observed in another electrochemical investigation of $\mathrm{CbA} 5 \mathrm{H}^{31}$. This inactivation at relatively low potential is reminiscent of the shift in the onset of anaerobic inactivation to lower potentials observed for DdH and HydA1 in the presence of exogenous sulfide ${ }^{30}$. When subsequently sweeping

the potential down, a faint increase in current, starting below $-0.25 \mathrm{~V}$, reveals the beginning of enzyme reactivation, which is complete only when the potential reaches $-0.6 \mathrm{~V}$. The C367D exchange causes a striking effect on the voltammetry (blue trace in Fig. 3a): the onset of inactivation occurs at a significantly 
Fig. 3 Electrochemical and spectroscopic features of $\mathbf{C b A 5 H} \mathbf{H T}^{\mathbf{W T}}$ and mutagenesis variants. a Comparison of cyclic voltammograms of $\mathrm{CbA5H} \mathrm{HT}^{\mathrm{W}}$ (Cb-WT), Cpl (Cpl-WT), and Cb-variant C367D $\left(\mathrm{T}=5^{\circ} \mathrm{C}, \mathrm{pH} 7,1 \mathrm{~atm}\right.$. of $\mathrm{H}_{2}$, scan rate $3 \mathrm{mV} / \mathrm{s}$, electrode rotation rate $3000 \mathrm{rpm}$, currents normalized at $\mathrm{E}=-0.56 \mathrm{~V})$. b Potential step chronoamperometry of $\mathrm{CbA} 5 \mathrm{H}^{\mathrm{WT}}$ and $\mathrm{C} 367 \mathrm{D}\left(5^{\circ} \mathrm{C}, \mathrm{pH} 7,1 \mathrm{~atm}\right.$. of $\left.\mathrm{H}_{2}, 1000 \mathrm{rpm}\right)$. P1: $\mathrm{H}_{2}-\mathrm{production}$ current at $-0.8 \mathrm{~V}$ prior to $\mathrm{O}_{2}$-exposure; P2: potential step to $0 \mathrm{~V} ; \mathbf{P 3}$ : injection of $50 \mu \mathrm{M} \mathrm{O}_{2} ; \mathbf{P 4}$ : five-fold buffer exchange to re-establish anaerobic conditions; P5: potential step to $-0.8 \mathrm{~V}$ to measure the residual $\mathrm{H}_{2}$-production current. c ATR-FTIR-spectroscopy of CbA5HWT and variant C367D prior and after $\mathrm{O}_{2}$-exposure ( $\mathrm{pH}$ 8). d Cyclic voltammograms of CbA5HWT (black) and mutagenesis variants $\mathrm{L} 364 \mathrm{~F}, \mathrm{P} 386 \mathrm{~L}, \mathrm{~A} 561 \mathrm{~F}$, and $\mathrm{L} 364 \mathrm{~F}-\mathrm{A} 561 \mathrm{~F}$ $\left(5^{\circ} \mathrm{C}, \mathrm{pH} 7,1 \mathrm{~atm}\right.$. of $\mathrm{H}_{2}, 20 \mathrm{mV} / \mathrm{s}, 3000 \mathrm{rpm}$, currents normalized at $\mathrm{E}=-0.32 \mathrm{~V}$ except $\mathrm{WT}$, at $-0.56 \mathrm{~V}$ ). e Chronoamperometry as in panel $\mathrm{B}$, with $\mathrm{CbA}_{5} \mathrm{H}^{\mathrm{WT}}$ and the same variants as in d. f ATR-FTIR-spectroscopy $\left(\mathrm{pH} 8\right.$ ) of the loop variants, prior, and after $\mathrm{O}_{2}$-exposure. Electrochemical and IR spectroscopic experiments have been repeated for each protein at 3-4 times with consistent results. Source data are provided in a source data file.

higher potential than for $\mathrm{CbA} 5 \mathrm{H}^{\mathrm{WT}}$, thus restoring a "standard" voltammetric signature. The latter is illustrated for $\mathrm{CpI}$ and HydA1 in Fig. 3a and Supplementary Figure 8, respectively: inactivation occurs at a much higher potential (above $0 \mathrm{~V}$ ) than for $\mathrm{CbA} 5 \mathrm{H}$, and reactivation begins below $-0.1 \mathrm{~V}$. The standard oxidative inactivation of [FeFe]-hydrogenases is fully dependent on the presence of chloride ions acting as uncompetitive inhibitors ${ }^{39}$. Inhibition by chloride is also observed for variant C367D, whereas chloride has only minor effects on CbA5H $\mathrm{HT}^{\mathrm{WT}}$ (Supplementary Figure 9). Anaerobic inactivation of standard hydrogenases and $\mathrm{CbA} 5 \mathrm{H}$-variant $\mathrm{C} 367 \mathrm{D}$ on the one hand, and $\mathrm{CbA} 5 \mathrm{H}^{\mathrm{WT}}$ on the other hand, therefore, result from distinct mechanisms.

To quantify and compare the $\mathrm{O}_{2}$-sensitivity of $\mathrm{CbA} 5 \mathrm{H}^{\mathrm{WT}}$ and variant $\mathrm{C} 367 \mathrm{D}$, we employed a PFE chronoamperometric procedure where the enzyme is exposed to $\mathrm{O}_{2}$ under oxidizing conditions, and the level of activity is measured under reductive conditions before and after exposure to $\mathrm{O}_{2}$ (Fig. 3b). The measured catalytic $\mathrm{H}_{2}$-evolution currents were normalized by the initial value recorded at the end of the 1 st step at low potential $(-0.3 \mathrm{~V})$. Upon switching the potential to $0 \mathrm{~V}, \mathrm{CbA} 5 \mathrm{H}^{\mathrm{WT}}$ instantly inactivates whereas $\mathrm{C} 367 \mathrm{D}$ retains $>95 \%$ of its $\mathrm{H}_{2}$ oxidation activity. Injecting $50 \mu \mathrm{M} \mathrm{O}_{2}$ into the electrochemical cell fully inhibits the C367D variant. After removal of $\mathrm{O}_{2}$ from the system by a five-fold buffer exchange and subsequently shifting the potential back to $-0.8 \mathrm{~V}, \mathrm{CbA} 5 \mathrm{H}^{\mathrm{WT}}$ returns to its original $\mathrm{H}^{+}$reduction activity, unlike variant $\mathrm{C} 367 \mathrm{D}$, which appears to have been completely and irreversibly inactivated by $\mathrm{O}_{2}$ exposure. These experiments demonstrate that anaerobic inactivation at relatively low potential and resistance to $\mathrm{O}_{2}$-induced damage both depend on C367.

As observed by IR-spectroscopy, exposure of $\mathrm{CbA} 5 \mathrm{H}^{\mathrm{WT}}$ to air induces a quantitative transition from $\mathrm{H}_{\mathrm{ox}}$ to $\mathrm{H}_{\text {inact }}$ (Fig. $3 \mathrm{c}$ and Supplementary Figure 1$)^{27}$. In contrast to wild-type enzyme, the $\mathrm{O}_{2}$-treated variants $\mathrm{C} 367 \mathrm{D}$ and $\mathrm{C} 367 \mathrm{~A}$ exhibit none of the IRvibrational signals characteristic of the $\mathrm{H}_{\text {inact }}$ state (Fig. $3 \mathrm{C}$ and Supplementary Figure 10). Under $\mathrm{N}_{2}$ atmosphere, the C367D variant exhibits strong $\mathrm{H}$-cluster signals which demonstrate a mixture of $\mathrm{H}_{\mathrm{ox}}$ and $\mathrm{H}_{\mathrm{ox}}-\mathrm{CO} . \mathrm{O}_{2}$-treatment of C367D leads, beside a small fraction of the inert $\mathrm{H}_{\mathrm{ox}}-\mathrm{CO}$ state (indicative of $\mathrm{H}$-cluster degradation as in ref. ${ }^{25}$ ), to a fast and nearly complete loss of the H-cluster specific IR-vibrational signals; this suggests that substantial cofactor degradation occurs, as observed for standard [FeFe]-hydrogenases ${ }^{24-26}$ (Supplementary Figure 10 and Supplementary Discussion 2 for the corresponding IR-spectroscopy data of variant $\mathrm{C} 367 \mathrm{~A}$ ).

We have therefore shown that (1) anaerobic inactivation, (2) $\mathrm{O}_{2}$-resistance, and (3) aerobic formation of $\mathrm{H}_{\text {inact }}$ all occur due to the presence of $\mathrm{C} 367$ which according to our structure of $\mathrm{CbA} 5 \mathrm{H}^{\text {air }}$ binds to $\mathrm{Fe}_{\mathrm{d}}$ in the $\mathrm{H}_{\text {inact }}$ state. This saturates the coordination sphere of $\mathrm{Fe}_{\mathrm{d}}$ and thus prevents the binding of substrate $\left(\mathrm{H}_{2}\right)$ and inhibitor $\left(\mathrm{O}_{2}\right)$ (Fig. 2d-e), rendering the enzyme inactive but protected from $\mathrm{O}_{2}$-induced degradation. That $\mathrm{CbA} 5 \mathrm{H}$ is quantitatively locked in the $\mathrm{H}_{\text {inact }}$ configuration is not only obvious from the homogenous IR-spectra of $\mathrm{O}_{2}$ treated enzyme but also from the low b-factor values observed for the $\mathrm{H}$ cluster environment in $\mathrm{CbA5H}^{\text {air }}$ (6TTL) including the fully shifted TSC-loop (Supplementary Fig. 16).

That both, aerobic and anaerobic oxidative conditions induce the formation of $\mathrm{H}_{\text {inact }}$ suggests that the sensing of oxidative conditions occurs via the two accessory [4Fe-4S]clusters (FS4B and FS4A in Fig. 2b). They mediate electron transfer between external redox partners and the H-cluster and can be oxidized either by the electrode at high potential or by transferring electrons to molecular oxygen. This reaction with $\mathrm{O}_{2}$ appears to be reversible.

Kinetics and mechanism of reversible anaerobic inactivation. We examined the kinetics and potential-dependence of anaerobic (in)activation, which can be quantitatively probed using PFE by potential-step experiments ${ }^{40}$. Figure 4 a shows a typical sequence of steps and the resulting change in current. Each initial current peak (e.g., at 50 or $100 \mathrm{~s}$ ) results from the turnover frequency of the fully active enzyme instantly changing after the potential is stepped up or down; the subsequent slow change in current results from the accordingly slow change in the concentration of the $\mathrm{H}_{\text {inact }}$ state. The data can be interpreted by assuming various kinetic models, which we tested by fitting them to the corresponding current traces ${ }^{41}$. A model that considers just two species (corresponding to the cysteine being either unbound or bound to $\mathrm{Fe}_{\mathrm{d}}$ ) and resulting in mono-exponential changes in current after each potential step is not satisfactory (green trace in Fig. 4a): the kinetic traces are multiphasic, and any good kinetic model must therefore include the conversions between at least three species (red trace in Fig. 4a). After having analyzed the data recorded at different potentials and $\mathrm{pH}$ values, we concluded that the simplest good model is the following, where A means "active", and $A_{1}$ and $\mathrm{A}_{2}$ are two distinct active species.

$$
\mathrm{A}_{1} \underset{\mathrm{k}_{-1}}{\stackrel{\mathrm{k}_{1}}{\leftrightarrows}} \mathrm{A}_{2} \underset{\mathrm{k}_{\text {react }}}{\stackrel{\mathrm{k}_{\text {inact }}}{\leftrightarrows}} \mathrm{H}_{\text {inact }}
$$

Fig. 4a shows the fit (red dotted line) of the above model to the chronoamperometric data, from which the values of the four rate constants can be determined at the two potentials used in the experiment. (see Supplementary Notes on the kinetic modeling of anaerobic inactivation of $\mathrm{CbA} 5 \mathrm{H}$ and Supplementary Figure 11).

Since the C367D mutation prevents the formation of $\mathrm{H}_{\text {inact }}$ and gives back $\mathrm{CbA} 5 \mathrm{H}$ standard catalytic properties, we assume that the structure of the active form $\mathrm{A}_{1}$ of $\mathrm{CbA} 5 \mathrm{H}$ is similar to that of standard hydrogenases, and that the difference between the structures of $\mathrm{CpI}$ and $\mathrm{CbA} 5 \mathrm{H}$ shown in Fig. 2e illustrates the conformational change that occurs upon the formation of $\mathrm{H}_{\text {inact }}$ from the active form $A_{1}$ of the enzyme. The conversion between the active forms $A_{1}$ and $A_{2}$ occurs on the time scale of seconds $\left(1 /\left(\mathrm{k}_{1}+\mathrm{k}_{-1}\right)=10 \mathrm{~s}\right)$ which implies that there must be a large activation energy barrier to overcome, probably due to a conformational change. In state $\mathrm{A}_{2}, \mathrm{C} 367$ cannot be bound to $\mathrm{Fe}_{\mathrm{d}}$, since $\mathrm{A}_{2}$ is still active (about half as active as $A_{1}$, 
a

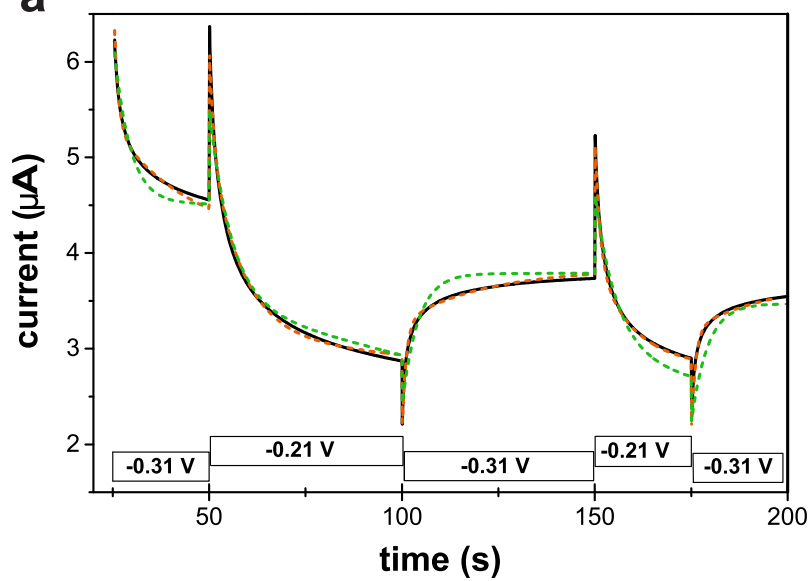

b

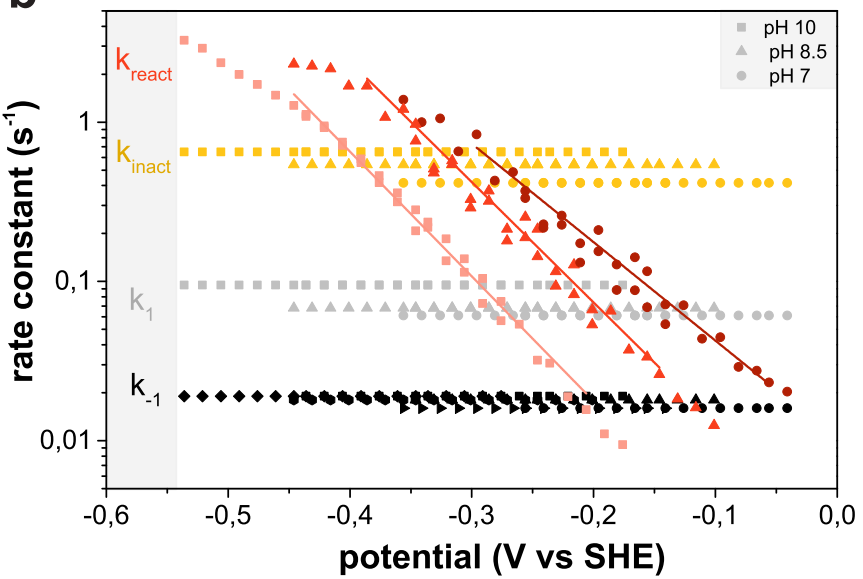

Fig. 4 Anaerobic conversion between active and inactive CbA5HWT monitored by PFE. a Chronoamperograms recorded to analyze the kinetics of anaerobic (in)activation of $\mathrm{CbA} 5 \mathrm{H}^{\mathrm{WT}}$ by stepping between -0.31 and $-0.21 \mathrm{~V}$. The boxes along the abscissa depict the sequence of applied potential steps and the corresponding current response (black line). The plot also shows the best fits of models that consider the interconversion between two (green dotted line) or three (red dotted line) species. Experimental parameters: $5^{\circ} \mathrm{C}, \mathrm{pH} 7,3000 \mathrm{rpm}$. b Dependence of the rate constants of the "AAI" model ( $\mathrm{A} 1 \leftrightarrow \mathrm{A} 2 \leftrightarrow \mathrm{H}_{\text {inact }}$ ) on potential and $\mathrm{pH}$, based on the analyses of chronoamperograms recorded for $\mathrm{CbA} 5 \mathrm{HWT}$ at $\mathrm{pH} 10$ (squares), 8.5 (triangle), and 7 (circle). Only $k_{\text {react }}$ significantly depends on $\mathrm{pH}$ and electrode potential. Source data are provided in a source data file.

Supplementary Figure 12). The binding of the cysteine sulfur to $\mathrm{Fe}_{\mathrm{d}}$ must therefore occur in the final step $\left(\mathrm{A}_{2}\right.$ to $\left.\mathrm{I}\right)$. That this bond is labile $\left(1 /\left(\mathrm{k}_{\text {inact }}+\mathrm{k}_{\text {react }}\right) \simeq 1 \mathrm{~s}\right.$ at high potential $)$ is consistent with the relatively long distance of $3.1 \AA$ between $\mathrm{Fe}_{\mathrm{d}}$ and the Satom of $\mathrm{C} 367$ observed in the structure of air-oxidized $\mathrm{CbA} 5 \mathrm{H}^{\mathrm{WT}}$. The reactivation from $\mathrm{H}_{\text {inact }}$ to $\mathrm{A}_{2}$ is the only step whose rate constant $\left(\mathrm{k}_{\text {react }}\right)$ depends on $\mathrm{pH}$ and the applied potential, showing that reactivation is triggered by a reduction step coupled to a protonation. At high potential, the reactivation rate constant $\mathrm{k}_{\text {react }}$ is lower than the inactivation rate constant $\mathrm{k}_{\text {inact }}$, locking down the enzyme in the $\mathrm{H}_{\text {inact }}$ state. The fact that $\mathrm{k}_{\text {inact }}$ is potential-independent points to a classical "CE" mechanism for step 2, in which one or a series of chemical step(s) (“C”) precede(s) proton-coupled oxidation ("E”). Strong coupling implies that the sites of deprotonation and oxidation are very close to one another. We therefore consider likely that this deprotonation occurs from the nitrogen atom of the azaditiolate bridge, or from the bound cysteine, to produce a thiolate ligand.

Three distal residues determine reversible $H_{\text {inact }}$-formation. The formation of $\mathrm{H}_{\text {inact }}$ as a result of cysteine binding to $\mathrm{Fe}_{\mathrm{d}}$ is a unique property of $\mathrm{CbA} 5 \mathrm{H}$, and yet $\mathrm{C} 367$ and the other residues of the shifted TSC-loop are strictly conserved (Supplementary Figure 5). Structural differences in their environment must therefore account for the loop-flexibility that enables the translocation of $\mathrm{C} 367$ in $\mathrm{CbA} 5 \mathrm{H}^{\mathrm{WT}}$. The most prominent differences between standard hydrogenases and $\mathrm{CbA} 5 \mathrm{H}^{\mathrm{WT}}$ near the TSCloop concern the residues at positions 364 (leucine), 561 (alanine) and 386 (proline) (Fig. 2e, f and Supplementary Figure 5): their backbones align with those of their counterparts in standard hydrogenases, but the latter exhibit bulkier residues.

To assess whether the residues at these positions determine the possibility of a conformational change and are responsible for the unique properties of $\mathrm{CbA} 5 \mathrm{H}$, we produced the $\mathrm{CbA} 5 \mathrm{H}$-variants L364F, A561F, P386L and the double-exchange variant L364F$\mathrm{A} 561 \mathrm{~F}$, and characterized them using the same combination of experiments as described above. Only variant $\mathrm{P} 386 \mathrm{~L}$ shows a reduced $\mathrm{H}_{2}$-evolution activity $\left(55 \%\right.$ compared to $\mathrm{CbA} 5 \mathrm{H}^{\mathrm{WT}}$, Supplementary Figure 7).

The cyclic voltammograms recorded with the four variants show reversible anaerobic inactivation, but at a significantly

\begin{tabular}{|c|c|c|c|c|}
\hline & $k_{1}\left(s^{-1}\right)$ & $k_{-1}\left(s^{-1}\right)$ & $k_{\text {inact }}\left(s^{-1}\right)$ & $k_{\text {react }}\left(s^{-1}\right)$ \\
\hline WT (pH 10) & 0.095 & 0.019 & 0.65 & 0.015 \\
\hline WT (pH 8.5) & 0.068 & 0.018 & 0.54 & 0.069 \\
\hline WT (pH 7) & 0.061 & 0.016 & 0.42 & 0.17 \\
\hline A561F (pH7) & 0.025 & 0.058 & 0.28 & 0.19 \\
\hline L364F（pH7） & 0.055 & 0.017 & 0.14 & 1.45 \\
\hline P386L (pH7) & 0.049 & 0.051 & 0.15 & 1.50 \\
\hline A561F-L364F (pH 7) & 0.017 & 0.067 & 0.13 & 2.09 \\
\hline Accuracy & $8 \%$ & $28 \%$ & $7 \%$ & $6 \%$ \\
\hline
\end{tabular}

Rate constants were obtained by analyzing kinetic data of anaerobic inactivation such as those shown in Fig. 4a with the "AAl" model (Supplementary Fig. 14 shows the dependence of $\mathrm{k}_{\text {react }}$ on E). The $\mathrm{CbA} 5 \mathrm{H}^{\mathrm{WT}}$ reference for the kinetic parameters of the variant proteins, measured at $\mathrm{pH} 7$ is marked in bold. The \% accuracy is our estimate of the maximal error for the determination of is marked in bold.

higher potential than observed for $\mathrm{CbA} 5 \mathrm{H}^{\mathrm{WT}}$ (Fig. 3d). We could fit the above kinetic model to the chronoamperometric data recorded with each of the mutants; the results in Table 1 confirm that the mutations hinder the $\mathrm{A}_{1}$ to $\mathrm{H}_{\text {inact }}$ conversion and inform about their individual effects on each of the two steps. The $\mathrm{L} 364 \mathrm{~F}$ and $\mathrm{P} 386 \mathrm{~L}$ substitutions decrease $\mathrm{k}_{\text {inact }}$ and increase $k_{\text {react }}$ (the $\mathrm{P} 386 \mathrm{~L}$ substitution also increases $\mathrm{k}_{-1}$, Table 1). The A561F substitution only significantly affects the $1^{\text {st }}$ step $\left(A_{1}\right.$ to $\left.A_{2}\right)$ : it decreases $k_{1}$ and increases $k_{-1}$ (Table 1 ). The double-exchange variant L364F-A561F combines the individual effects of the two single exchanges.

Figure $3 \mathrm{e}$ shows that each of the substitutions also decreases $\mathrm{O}_{2}$-resistance. Each of the variants exhibited some residual level of activity just after the first potential step from $-0.8 \mathrm{~V}$ to $0 \mathrm{~V}$, followed by an inactivation that is slower than that of $\mathrm{CbA} 5 \mathrm{H}^{\mathrm{WT}}$. After buffer exchange and the final step to $-0.8 \mathrm{~V}$, the residual activities of all single-exchange variants are down to $76-64 \%$ and the double-exchange variant merely reaches $34 \%$ of the activity recorded prior to $\mathrm{O}_{2}$-exposure, compared to $100 \%$ for $\mathrm{CbA} 5 \mathrm{H}^{\mathrm{WT}}$ (also in Fig. 3b). These results show that resistance to $\mathrm{O}_{2}$ correlates with the overall rate of formation of the inactive state 


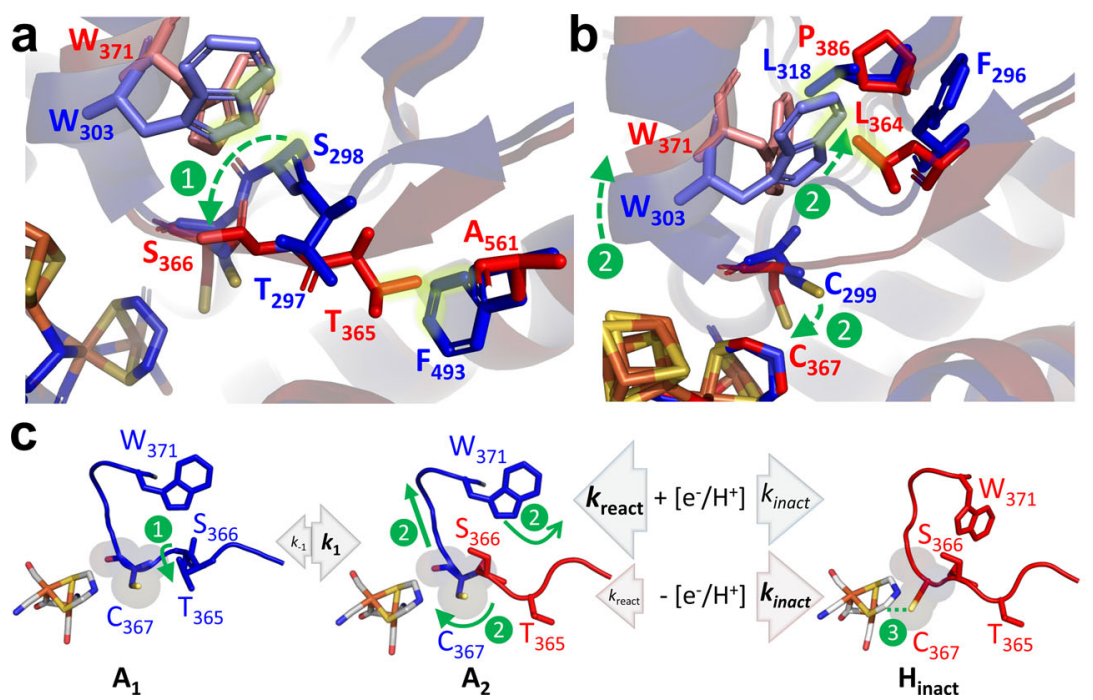

Fig. $\mathbf{5}$ Mechanism for the reversible formation of the $\mathbf{O}_{\mathbf{2}}$-resistant $\mathbf{H}_{\text {inact }}$ state in $\mathbf{C b A 5} \mathbf{H}^{\mathbf{W T}}$. a, $\mathbf{b}$ Structural alignment of $\mathrm{Cpl}$ (state $\mathrm{A}_{1}$, blue) and $\mathrm{CbA} 5 \mathrm{H}^{\mathrm{air}}$ $\left(\mathrm{H}_{\text {inact; }}\right.$ red) focusing on the TSC-loop. Residues labeled in red determine the structural rearrangement from $\mathrm{A}_{1}$ to $\mathrm{H}_{\text {inact. }}$. Corresponding $\mathrm{Cpl}$ positions are shown in blue (yellow glow indicates clashes). c lllustration of the AAl mechanism. Main steps (1-3) in the transition from $A_{1}$ (blue) to $H_{\text {inact }}$ (red) via $A_{2}$ (blue-red) are marked in green, corresponding to structural rearrangements (1-3) shown in a-b. 1: Partial shift of the TSC-loop, including T365, initiating the $A_{1}$ to $A_{2}$ transition. 2: W371-translocation and $\alpha$-helix uplift, dragging along C367 closer to Fe (green arrows) 3: Binding of C367 to Fe $e_{d}$ (dotted green line) and oxidation of the $\mathrm{H}$-cluster yields the inactive but $\mathrm{O}_{2}$-resistant $\mathrm{H}_{\text {inact }}$ state. Arrow and font sizes reflect relative rates of $\mathrm{k}_{1}$ and $\mathrm{k}_{-1}$ or $\mathrm{k}_{\text {inact }}$ and $\mathrm{k}_{\text {react, }}$ in $\mathrm{CbA} 5 \mathrm{H}$, which define the dynamic equilibrium between $\mathrm{A}_{1}, \mathrm{~A}_{2}$, and $\mathrm{H}_{\text {inact }}$. Under reductive conditions $\left(+\mathrm{e}^{-} / \mathrm{H}^{+}\right)$the $\mathrm{k}_{\text {inact }} / \mathrm{k}_{\text {react }}$ ratio favors $\mathrm{A}_{2}$, whereas $\mathrm{H}_{\text {inact }}$ accumulates under oxidative conditions $\left(-\mathrm{e}^{-} / \mathrm{H}^{+}\right)$.

under oxidizing conditions, which increases in the order $\mathrm{WT}<$ $\mathrm{L} 364 \mathrm{~F} \approx \mathrm{P} 386 \mathrm{~L} \approx \mathrm{A} 561 \mathrm{~F}<\mathrm{L} 364 \mathrm{~F}-\mathrm{A} 561 \mathrm{~F}<\mathrm{C} 367 \mathrm{D}$.

Monitoring the IR-signatures of the $\mathrm{H}$-cluster confirms that the residual $\mathrm{O}_{2}$-resistance of the variants results from the formation of a residual fraction of $\mathrm{H}_{\text {inact }}$ (Fig. $3 \mathrm{f}$ and Supplementary Figure 13). Prior to $\mathrm{O}_{2}$-treatment, all variants show the signature of the $\mathrm{H}_{\mathrm{ox}}$ state, with minor contributions from $\mathrm{H}_{\mathrm{ox}}-\mathrm{CO}$. However, unlike the case of $\mathrm{CbA} 5 \mathrm{H}^{\mathrm{WT}}$ (Fig. 3c), these signals disappear upon exposure to air. The only remaining signals after $\mathrm{O}_{2}$-treatment result from $\mathrm{H}_{\text {ox }}-\mathrm{CO}$ and a small fraction of $\mathrm{H}_{\text {inact }}$ which is just above noise level for L364F and P386L, and barely visible for L364F-A561F, thus contrasting with the clear and homogenous $\mathrm{H}_{\text {inact }}$ spectrum of $\mathrm{CbA} 5 \mathrm{H}^{\mathrm{WT}}$.

We therefore conclude that each of the three substitutions that were expected to alter the flexibility of the TSC-loop slows down oxidative inactivation, limits the extent of $\mathrm{H}_{\text {inact }}$-formation and, consequently, decreases the resistance of $\mathrm{CbA} 5 \mathrm{H}$ to $\mathrm{O}_{2}$. The exchanges have distinct effects on the two steps of the inactivation process (Table 1), and this information is used hereafter to elucidate the conformational change occurring upon formation of $\mathrm{H}_{\text {inact }}$.

In summary, we deduce the events leading to oxidative inactivation and accumulation of $\mathrm{H}_{\text {inact }}$ according to the AAI model (Table 1 and Fig. 5) as follows.

The first step of the conformational change (from state $A_{1}$, as observed in the structure of $\mathrm{CpI}$, to $\mathrm{A}_{2}$ ) cannot move C367 significantly closer to $\mathrm{Fe}_{\mathrm{d}}$ since $\mathrm{A}_{2}$ is still active. We consider likely that the $\mathrm{A}_{1} / \mathrm{A}_{2}$ transition which involves a turn of the segment including CbA5H-T365 and -S366 in the TSC-loop (equivalent to T297 and S298 in CpI) (Fig. 5a, c, step 1), consistent with this first step being slowed only by the A561F substitution (Table 1) which induces a steric clash with T365 of $\mathrm{CbA}_{5} \mathrm{H}^{\text {air }}$ (Fig. 5a). This movement of T365 and S366 requires a reorganization of the $\mathrm{H}$-bond network that stabilizes TSC loop configuration $\mathrm{A}_{1}$, including a disruption of the $\mathrm{H}$-bond contact between the $\mathrm{N}$-atom of the indole ring and the carbonyl oxygen of T365 (Supplementary Fig. 15) and provides the necessary space for the subsequent translocation of W371 (see clash between Trp (red) and Ser (blue) in its original position of state $A_{1}$ in Fig. 5a) and of the alpha helix that bears it (Fig. 5b, c; step 2). The substitution L364F favors state $\mathrm{A}_{2}$ over $\mathrm{H}_{\text {inact }}$ (Table 1) because it removes the slight steric clash between L364 and the W371 in state $A_{2}$ (Fig. 5b, blue Trp). The conformational shift of W371 in step 2 should be slowed when P386 is replaced with leucine (see clashes between W371 of $\mathrm{CbA}_{5} \mathrm{H}^{\text {air }}$ and L318 of CpI in Fig. 5b), which is consistent with the transition from $\mathrm{A}_{2}$ to $\mathrm{H}_{\text {inact }}$ being disfavored in variant P386L (Table 1). Step 2 brings C367 close enough to $\mathrm{Fe}_{\mathrm{d}}$ to allow its coordination (Fig. 5c, step 3), which should favor cluster oxidation and deprotonation (probably of the bound cysteine). This oxidation step finally locks down the enzyme in the $\mathrm{H}_{\text {inact }}$-state.

The protective function of the thiolate group described here is analogous to that of exogenous sulfide demonstrated for several standard $[\mathrm{FeFe}]$-hydrogenases ${ }^{30}$. Sulfide, the main product of the sulphate metabolism of $D$. desulfuricans, could be trapped near the $\mathrm{H}$-cluster and be quickly relocated under oxidative conditions to the open coordination site of $\mathrm{Fe}_{\mathrm{d}}$ in order to shield it against $\mathrm{O}_{2}$-attack. To make use of this effect, the presence of extrinsic sulfide as a potential-dependent $\mathrm{H}$ cluster inhibitor would be mandatory. Likewise relying on the capability of a sulfur ligand to reversibly occupy the substrate coordination site of the $\mathrm{H}$-cluster, $\mathrm{CbA} 5 \mathrm{H}$ adopts the same protected state as $\mathrm{DdH}$ but independent of the presence of external $\mathrm{S}^{2-}$. The intrinsic security cap may have been the consequence of evolutionary pressure to cope with incidental $\mathrm{O}_{2}$-exposure in the absence of abundant sulfide.

Our study exemplifies how amino acid residues that are located far from the active site, still may determine the ability to undergo a conformational change which controls chemistry in the 1st coordination sphere, allowing e.g. the enzyme to resist $\mathrm{O}_{2}$ attack. Enzymes benefit from the multiplicity of structural and functional features of the protein scaffold in ways that are far more elaborate 
than merely providing a cofactor cavity that stabilizes and tunes the properties of the active site, and substrate/product pathways. The intrinsic cofactor protection mechanism of $\mathrm{CbA5H}$ is an impressive showcase for the level of complexity that such additional contributions may reach under corresponding evolutionary pressure.

\section{Methods}

Protein preparation. The cDNA used for heterologous overexpression of $\mathrm{CbA} 5 \mathrm{H}$ was codon optimized for Escherichia coli strain K12 and synthesized with a Cterminal spacer and strep-tagII sequence ${ }^{27}$ before being cloned into the pET21b vector, where gene expression is controlled by the T7 promotor. QuikChange PCR was carried out to generate the constructs for the expression of site directed mutagenesis (SDM) variants using mismatch primers (Supplementary Table 3) ${ }^{18}$. Expression constructs were characterized via sequencing.

Protein expression, purification, and in vitro maturation were executed as described before ${ }^{6,18}$. Briefly, apo-forms of CbA5H (wild-type and variants) and CpI lacking the $[2 \mathrm{Fe} 2 \mathrm{~S}]$-subcluster $\left([2 \mathrm{Fe}]_{\mathrm{H}}\right)$ of the $\mathrm{H}$-cluster were expressed in Escherichia coli BL21 (DE3) $\Delta i s c R^{42}$. Affinity chromatography was applied to isolate the protein under strictly anaerobic conditions in a glove box (Coy Laboratory Products, USA). The purity of the isolate was verified by SDSpolyacrylamide gel electrophoresis and protein concentration was determined via Bradford assay. The purified apo-proteins were incubated with artificially synthesized $[2 \mathrm{Fe}]_{\mathrm{H}}$-mimic $\left(\mathrm{Fe}_{2}\left[\mu-\left(\mathrm{SCH}_{2}\right)_{2} \mathrm{NH}\right](\mathrm{CN})_{2}(\mathrm{CO})_{4}\left[\mathrm{Et}_{4} \mathrm{~N}\right]_{2}\right)$ to reconstitute active protein and excess of the $[2 \mathrm{Fe}]_{\mathrm{H}}$ mimic was removed by size-exclusion chromatography ${ }^{43}$. The $[2 \mathrm{Fe}]_{\mathrm{H}}$ mimic used for in vitro maturation was synthesized as described before ${ }^{44}$.

In vitro activity assay. To perform $\mathrm{H}_{2}$-production activity assays, $400 \mathrm{ng}$ enzyme was mixed with $100 \mathrm{mM} \mathrm{NaDT}$ (sodium dithionite) as sacrificial electron donor and $10 \mathrm{mM} \mathrm{MV} \mathrm{(methyl} \mathrm{viologen)} \mathrm{as} \mathrm{electron} \mathrm{mediator} \mathrm{in} 100 \mathrm{mM}$ $\mathrm{K}_{2} \mathrm{HPO}_{4} / \mathrm{KH}_{2} \mathrm{PO}_{4}$ buffer ( $\mathrm{pH} 6.8$ ). The sealed reaction vessel was kept at $37^{\circ} \mathrm{C}$ in a shaking incubator $(100 \mathrm{rpm})^{6,18,43}$. The evolved $\mathrm{H}_{2}$ was quantified by analyzing the headspace of the reaction tube via gas chromatography (Shimadzu). To monitor the $\mathrm{pH}$-dependent $\mathrm{H}_{2}$-production activity, the phosphate buffer was substituted with the respective pH-selective buffers (pH 5 to $\mathrm{pH} 9)^{6,18}$. Each measurement was done at least three times (see mean values and standard deviations in Supplementary Figure 7).

Crystallization and structure determination. Despite the strictly anaerobic handling of $\mathrm{CbA5} \mathrm{H}^{\mathrm{WT}}$ during purification and maturation, protein crystallization was done aerobically (under air). $\mathrm{CbA} 5 \mathrm{H}$ crystals were obtained using the hanging drop vapor diffusion method. $2 \mu \mathrm{l}$ protein $(20-40 \mathrm{mg} / \mathrm{ml})$ was mixed with $2 \mu \mathrm{l}$ reservoir solution, containing 0.1 M HEPES pH 7.5 (4-(2-hydroxyethyl)-1-piperazineethanesulfonic acid), $0.4 \mathrm{M} \mathrm{MgCl}_{2}$ and $26-28 \%$ PEG400 (polyethylene glycol of molecular weight c.a. $400 \mathrm{Da}$ ). The crystals were grown at $18^{\circ} \mathrm{C}$ and reached full size within one week. Before flash freezing in liquid $\mathrm{N}_{2}$, the crystals were soaked for a few seconds in cryobuffer, being a premix of reservoir solution and $100 \%$ glycerol at a 1:1 ratio. X-ray diffraction data were collected on beamline ID29 at the European Synchrotron Radiation Facility (ESRF, Grenoble, France) at $100 \mathrm{~K}$. Diffraction images were processed with XDS and the processed data were reduced and combined by running XSCALE ${ }^{45}$. Molecular replacement was carried out in Phaser ${ }^{46}$ to obtain the phase. Initially, no satisfactory solutions were obtained by using either of the three homologous structures CpI (4XDC), DdH (1HFE) or HydA1 (3LX4). However, a manually trimmed model of CpI (4XDC), in which the non-conserved part was removed based on a sequence alignment, yielded a solution with TFZ (translation function Z) and LLG (log likelihood gain) scores of 14.7 and 137, respectively. Subsequently, Phenix Autobuild was used to generate the model $^{47}$. The first round of Autobuild resulted in an improved model with an $\mathrm{R}_{\text {free }}$ of 0.38 . The model was then further optimized, using alternative rounds of interactive building in $\mathrm{Coot}^{48}$ and automatic refinement in Phenix. Group occupancy was refined for the iron sulfur clusters. The final model and structure factor were deposited at RCSB protein data bank (PDB ID: 6TTL). Statistics for data collection and refinement are summarized in Supplementary Tables 1,2 . To verify placement of critical parts of the model, simulated annealing omit maps were calculated in Phenix after removing the relevant parts from the input model.

ATR-FTIR-Spectroscopy. FTIR-spectra were collected on a Bruker Tensor 27 spectrometer, equipped with a BioATR cell II (Harrick) harboring a doublereflection $\mathrm{ZnSe} / \mathrm{Si}$ crystal. Prior to all measurements, the sample $(15 \mu \mathrm{L})$ was dried at $30^{\circ} \mathrm{C}$ on the ATR crystal under $\mathrm{N}_{2}(10 \mathrm{~L} / \mathrm{min})$ to enrich the oxidized ready state $\mathrm{H}_{\mathrm{ox}}$. A semi-dried protein film was usually obtained after 10 minutes. The film was re-humidified by purging with an aerosol (Tris buffer, $\mathrm{pH} 8$ ) and the temperature was decreased to $25^{\circ} \mathrm{C}$ before the measurements were started $\left(2 \mathrm{~cm}^{-1} \text { resolution }\right)^{49}$. The recorded spectra were baseline corrected via OPUS (Bruker GmbH) and then imported and plotted by Origin (Origin Lab). For each enzyme variant, the experiment was repeated two times, showing no significant deviations.

\section{Electrochemical experiments}

Cyclic voltammetry in Fig. 3 and chronoamperometry in Fig. 4. Cyclic voltammetry and the amperometry experiments employed to elucidate the kinetics of the conformational change leading to $\mathrm{H}_{\text {inact }}$-formation were carried out in a JACOMEX glovebox filled with $\mathrm{N}_{2}$ in a thermostated $\left(T=5^{\circ} \mathrm{C}\right)$ electrochemical cell with two compartments. The main compartment contained the rotating working electrode (pyrolytic graphite edge, diameter $\sim 3 \mathrm{~mm}$, typical rotation rate $3 \mathrm{krpm}$, mounted on a Pine MSR rotator) and the counter electrode (a platinum wire) as well as a tube for constant $\mathrm{H}_{2}$-bubbling. Unless stated otherwise, the main compartment was filled with a mixed buffered solution (consisting of $5 \mathrm{mM}$ of each MES, HEPES, sodium acetate, TAPS, and CHES and $0.1 \mathrm{M} \mathrm{NaCl}$ ). The main compartment was connected via a Luggin capillary to a second compartment, containing the calomel reference electrode in $0.1 \mathrm{M} \mathrm{NaCl}$ All potentials are quoted with respect to the standard hydrogen electrode, calculated using $E_{\mathrm{SHE}}=E_{\text {calomel }}+0.244 \mathrm{~V}$

To prepare the protein films, the pyrolytic graphite "edge" (PGE) rotating disc working electrode was polished with an aqueous alumina slurry (Buehler, $1 \mu \mathrm{m}$ ), rinsed, then painted with $0.5 \mu \mathrm{l}$ of an enzyme solution $(\sim 5 \mathrm{mg} / \mathrm{mL}$ in $100 \mathrm{mM}$ Tris$\mathrm{HCl}, \mathrm{pH} 8$ with $2 \mathrm{mM} \mathrm{NaDT}$ ) and let dry for $2 \mathrm{~min}$. The measured catalytic currents were between 1- and $10 \mu \mathrm{A}$, so that mass transport towards the rotating electrode was not limiting ${ }^{50}$.

CVs and chronoamperometric experiments were recorded with the program GPES and analyzed with the open source program QSoas ${ }^{41}$. Chronoamperometric experiments such as those presented in Fig. 4a were started and ended at a potential $30 \mathrm{mV}$ below the equilibrium potential $(\mathrm{pH} 7:-0.456 \mathrm{~V}$ vs SHE, $\mathrm{pH} 8.5:-0.546 \mathrm{~V}$, $\mathrm{pH} 10:-0.636 \mathrm{~V})$ to ensure complete activation of the enzyme film. The intermediate steps at oxidative potential were of $100 \mathrm{mV}$ amplitude. Before analyzing the $\mathrm{H}_{2}$-oxidation current, we subtracted the background capacitive current recorded in a control experiment without enzyme.

Chronoamperometry in Fig. 3. Experiments were carried out in an anaerobic chamber (Coy Laboratory Products, USA) under an atmosphere of $98 \% \mathrm{~N}_{2}$ and $2 \% \mathrm{H}_{2}$. A PalmSens potentiostat (PalmSens 4) was used, controlled by the PalmSens software PSTrace 5.2. The gastight electrochemical cell was water jacketed to control the temperature and a PGE rotating disc electrode was used as a working electrode and controlled by a rotator (Autolab). The reference electrode $(\mathrm{Ag} / \mathrm{AgCl}, 3.5 \mathrm{M} \mathrm{KCl})$ was kept in a non-isothermal side arm, being connected to the main cell compartment by a Luggin capillary. Platinum wire was used as a counter electrode. The reference potential was converted to the standard hydrogen electrode (SHE) scale, using the correction $E_{\mathrm{SHE}}=E_{\mathrm{Ag} / \mathrm{AgCl}}+$ $0.205 \mathrm{~V}$ at $20^{\circ} \mathrm{C}$. For each experiment, defined gas flow rates (Air liquid, Germany) were adjusted, using mass flow controllers (Sierra Instruments). Enzyme films were prepared by drop-casting $3 \mu \mathrm{L}$ of a $10 \mu \mathrm{M}$ hydrogenase sample. After 3 minutes, the electrode was rinsed with MQ water to remove all unbound enzyme molecules. Prior to the potential step experiment, a cyclic voltammogram was recorded for each enzyme film $\left(5^{\circ} \mathrm{C}, \mathrm{pH} 7,1000 \mathrm{rpm}\right.$ electrode rotation, $100 \% \mathrm{H}_{2}$ atmosphere, from -1 to $0 \mathrm{~V}$, using a scan rate of $20 \mathrm{mV} / \mathrm{s}$ ). For the chronoamperometric experiments, a potential of $-0.8 \mathrm{~V}$ vs SHE was applied for $200 \mathrm{~s}$ (Phase $1, \mathrm{t}=0 \mathrm{~s}$ ) to monitor $\mathrm{H}^{+}$reduction activity. A potential step to $0 \mathrm{~V}$ vs SHE (phase $2, \mathrm{t}=200 \mathrm{~s}$ ) was followed by the injection of $50 \mu \mathrm{M} \mathrm{O}_{2}$ (using air-saturated buffer, phase $3, \mathrm{t}=480 \mathrm{~s}$ ). A subsequent five-fold buffer exchange $\left(5 \mathrm{~mL}\right.$ cell volume, $50 \mathrm{~mL}$ volume exchange buffer, incubated at $\left.5{ }^{\circ} \mathrm{C}\right)$ was performed to reestablish anaerobic conditions (phase $4, \mathrm{t}=900 \mathrm{~s}$ ) prior to the final potential step back to $-0.8 \mathrm{~V}$ vs SHE (phase $5, \mathrm{t}=1300 \mathrm{~s}$ ) which was required to measure the residual $\mathrm{H}^{+}$reduction current. For each enzyme variant the experiment was repeated at least 4 times, showing very similar results.

Reporting Summary. Further information on research design is available in the Nature Research Reporting Summary linked to this article.

\section{Data availability}

The coordinates and structure factors of $\mathrm{CbA} 5 \mathrm{H}^{\text {air }}$ have been deposited in protein data bank (PDB) under PDB-ID: 6TTL All data are available in the main text or the supplementary materials. Further data supporting findings of this study are available from the corresponding authors upon reasonable request. Further publicly available datasets used or indicated in this study comprise PDB-ID: 4XDC, PDB-ID: 3LX4 and PDB-ID: 1HFE. Source data are provided with this paper.

Received: 16 June 2020; Accepted: 16 December 2020; Published online: 02 February 2021

\section{References}

1. Fontecilla-Camps, J. C., Volbeda, A., Cavazza, C. \& Nicolet, Y. Structure/ function relationships of $[\mathrm{NiFe}]-$ and $[\mathrm{FeFe}]$-hydrogenases. Chem. Rev. 107, 4273-4303 (2007). 
2. Hexter, S. V., Grey, F., Happe, T., Climent, V. \& Armstrong, F. A. Electrocatalytic mechanism of reversible hydrogen cycling by enzymes and distinctions between the major classes of hydrogenases. Proc. Natl Acad. Sci. USA 109, 11516-11521 (2012).

3. Peters, J. W. et al. [FeFe]- and [NiFe]-hydrogenase diversity, mechanism, and maturation. Biochimica et. biophysica acta 1853, 1350-1369 (2015).

4. Peters, J. W., Lanzilotta, W. N., Lemon, B. J. \& Seefeldt, L. C. X-ray crystal structure of the Fe-only hydrogenase (CpI) from Clostridium pasteurianum to 1.8 angstrom resolution. Science 282, 1853-1858 (1998).

5. Sommer, C. et al. Proton coupled electronic rearrangement within the $\mathrm{H}$ Cluster as an essential step in the catalytic cycle of [FeFe] hydrogenases. J. Am. Chem. Soc. 139, 1440-1443 (2017).

6. Winkler, M. et al. Accumulating the hydride state in the catalytic cycle of [FeFe]-hydrogenases. Nat. Commun. 8, 16115 (2017)

7. Senger, M. et al. Protonation/reduction dynamics at the $[4 \mathrm{Fe}-4 \mathrm{~S}]$ cluster of the hydrogen-forming cofactor in [FeFe]-hydrogenases. Phys. Chem. Chem. 20, 3128-3140 (2018).

8. Bruschi, M. et al. Influence of the $[2 \mathrm{Fe}]_{\mathrm{H}}$ subcluster environment on the properties of key intermediates in the catalytic cycle of [FeFe] hydrogenases: hints for the rational design of synthetic catalysts. Angew. Chem. 48, 3503-3506 (2009).

9. Esselborn, J. et al. A structural view of synthetic cofactor integration into [FeFe]-hydrogenases. Chem. Sci. 7, 959-968 (2016).

10. Goldet, G. et al. Electrochemical kinetic investigations of the reactions of [FeFe]-hydrogenases with carbon monoxide and oxygen: comparing the importance of gas tunnels and active-site electronic/redox effects. J. Am. Chem. Soc. 131, 14979-14989 (2009).

11. Kubas, A. et al. Mechanism of $\mathrm{O}_{2}$ diffusion and reduction in $\mathrm{FeFe}$ hydrogenases. Nat. Chem. 9, 88-95 (2017).

12. Stripp, S. T. et al. How oxygen attacks [FeFe] hydrogenases from photosynthetic organisms. Proc. Natl Acad. Sci. USA 106, 17331-17336 (2009).

13. Wait, A. F. et al. Formaldehyde-a rapid and reversible inhibitor of hydrogen production by [FeFe]-hydrogenases. J. Am. Chem. Soc. 133, 1282-1285 (2011).

14. Baffert, C. et al. Hydrogen-activating enzymes: activity does not correlate with oxygen sensitivity. Angew. Chem. 47, 2052-2054 (2008).

15. Cornish, A. J., Gartner, K., Yang, H., Peters, J. W. \& Hegg, E. L. Mechanism of proton transfer in [FeFe]-hydrogenase from Clostridium pasteurianum. J. Biol. Chem. 286, 38341-38347 (2011).

16. Morra, S. et al. Site saturation mutagenesis demonstrates a central role for cysteine 298 as proton donor to the catalytic site in CaHydA [FeFe]hydrogenase. PloS one 7, e48400 (2012).

17. Ginovska-Pangovska, B. et al. Molecular dynamics study of the proposed proton transport pathways in [FeFe]-hydrogenase. Biochimica et. biophysica acta 1837, 131-138 (2014).

18. Duan, J. et al. Crystallographic and spectroscopic assignment of the proton transfer pathway in [FeFe]-hydrogenases. Nat. Commun. 9, 4726 (2018).

19. Liebgott, P. P. et al. Relating diffusion along the substrate tunnel and oxygen sensitivity in hydrogenase. Nat. Chem. Biol. 6, 63-70 (2010).

20. Mohammadi, M. \& Vashisth, H. Pathways and thermodynamics of oxygen diffusion in [FeFe]-hydrogenase. J. Phys. Chem. B 121, 10007-10017 (2017)

21. Cohen, J., Kim, K., King, P., Seibert, M. \& Schulten, K. Finding gas diffusion pathways in proteins: application to $\mathrm{O}_{2}$ and $\mathrm{H}_{2}$ transport in $\mathrm{CpI}$ [FeFe]hydrogenase and the role of packing defects. Structure 13, 1321-1329 (2005).

22. Bruska, M. K., Stiebritz, M. T. \& Reiher, M. Regioselectivity of H-cluster oxidation. J. Am. Chem. Soc. 133, 20588-20603 (2011).

23. Mebs, S. et al. Hydrogen and oxygen trapping at the H-cluster of [FeFe]hydrogenase revealed by site-selective spectroscopy and QM/MM calculations. Biochimica et. biophysica acta 1859, 28-41 (2018).

24. Noth, J. et al. Lyophilization protects [FeFe]-hydrogenases against $\mathrm{O}_{2}$-induced H-cluster degradation. Sci. Rep. 5, 13978 (2015).

25. Swanson, K. D. et al. [FeFe]-hydrogenase oxygen inactivation is initiated at the H-cluster 2Fe subcluster. J. Am. Chem. Soc. 137, 1809-1816 (2015).

26. Esselborn, J., Kertess, L., Apfel, U. P., Hofmann, E. \& Happe, T. Loss of specific active-site iron atoms in oxygen-exposed [FeFe]-hydrogenase determined by Detailed X-ray structure analyses. J. Am. Chem. Soc. 141, 17721-17728 (2019).

27. Morra, S., Arizzi, M., Valetti, F. \& Gilardi, G. Oxygen Stability in the New [FeFe]-Hydrogenase from Clostridium beijerinckii SM10 (CbA5H). Biochemistry 55, 5897-5900 (2016).

28. Roseboom, W., De Lacey, A. L., Fernandez, V. M., Hatchikian, E. C. \& Albracht, S. P. The active site of the [FeFe]-hydrogenase from Desulfovibrio desulfuricans. II. Redox properties, light sensitivity and CO-ligand exchange as observed by infrared spectroscopy. J. Biol. Inorg. Chem. 11, 102-118 (2006).

29. Glick, B. R., Martin, W. G. \& Martin, S. M. Purification and properties of the periplasmic hydrogenase from Desulfovibrio desulfuricans. Can. J. Microbiol. 26, 1214-1223 (1980).

30. Rodríguez-Maciá, P. et al. Sulfide Protects [FeFe] Hydrogenases From $\mathrm{O}_{2}$. J. Am. Chem. Soc. 140, 9346-9350 (2018).
31. Corrigan, P. S., Tirsch, J. L. \& Silakov, A. Investigation of the unusual ability of the $[\mathrm{FeFe}]$ Hydrogenase from Clostridium beijerinckii to Access an $\mathrm{O}_{2}$ Protected State. J. Am. Chem. Soc. 142, 12409-12419 (2020).

32. Artz, J. H. et al. Tuning catalytic bias of hydrogen gas producing hydrogenases. J. Am. Chem. Soc. 142, 1227-1235 (2020)

33. Nicolet, Y., Piras, C., Legrand, P., Hatchikian, C. E. \& Fontecilla-Camps, J. C. Desulfovibrio desulfuricans iron hydrogenase: the structure shows unusual coordination to an active site Fe binuclear center. Structure 7, 13-23 (1999).

34. Krest, C. M. et al. Significantly shorter Fe-S bond in cytochrome P450-I is consistent with greater reactivity relative to chloroperoxidase. Nat. Chem. 7, 696-702 (2015)

35. Armstrong, F. A., Evans, R. M. \& Megarity, C. F. Protein film electrochemistry of iron-sulfur enzymes. Methods Enzymol. 599, 387-407 (2018).

36. Sensi, M., del Barrio, M., Baffert, C., Fourmond, V. \& Léger, C. New perspectives in hydrogenase direct electrochemistry. Curr. Opin. Electrochemistry 5, 135-145 (2017).

37. Orain, C. et al. Electrochemical measurements of the kinetics of inhibition of two $\mathrm{FeFe}$ hydrogenases by $\mathrm{O}_{2}$ demonstrate that the reaction is partly reversible. J. Am. Chem. Soc. 137, 12580-12587 (2015).

38. Fourmond, V., Wiedner, E. S., Shaw, W. J. \& Leger, C. Understanding and design of bidirectional and reversible catalysts of multielectron, multistep reactions. J. Am. Chem. Soc. 141, 11269-11285 (2019).

39. Del Barrio, M. et al. Interaction of the H-Cluster of FeFe hydrogenase with halides. J. Am. Chem. Soc. 140, 5485-5492 (2018).

40. del Barrio, M. \& Fourmond, V. Redox (In)activations of metalloenzymes: a protein film voltammetry approach. ChemElectroChem 6, 4949-4962 (2019).

41. Fourmond, V. QSoas: a versatile software for data analysis. Anal. Chem. 88, 5050-5052 (2016).

42. Akhtar, M. K. \& Jones, P. R. Deletion of $i s c R$ stimulates recombinant clostridial Fe-Fe hydrogenase activity and $\mathrm{H}_{2}$-accumulation in Escherichia coli BL21(DE3). Appl. Microbiol. Biotechnol. 78, 853-862 (2008).

43. Esselborn, J. et al. Spontaneous activation of [FeFe]-hydrogenases by an inorganic [2Fe] active site mimic. Nat. Chem. Biol. 9, 607-609 (2013).

44. Li, H. \& Rauchfuss, T. B. Iron carbonyl sulfides, formaldehyde, and amines condense to give the proposed azadithiolate cofactor of the Fe-only hydrogenases. J. Am. Chem. Soc. 124, 726-727 (2002).

45. Kabsch, W. Integration, scaling, space-group assignment and post-refinement. Acta Crystallogr. Sect. D., Biol. Crystallogr. 66, 133-144 (2010).

46. McCoy, A. J. et al. Phaser crystallographic software. J. Appl. Crystallogr. 40, 658-674 (2007)

47. Terwilliger, T. C. et al. Iterative model building, structure refinement and density modification with the PHENIX AutoBuild wizard. Acta Crystallogr. Sect. D., Biol. Crystallogr. 64, 61-69 (2008).

48. Emsley, P. \& Cowtan, K. Coot: model-building tools for molecular graphics. Acta Crystallogr. Sect. D., Biol. Crystallogr. 60, 2126-2132 (2004).

49. Lampret, O. et al. The final steps of [FeFe]-hydrogenase maturation. Proc. Natl Acad. Sci. USA 116, 15802-15810 (2019).

50. Merrouch, M., Hadj-Saïd, J., Léger, C., Dementin, S. \& Fourmond, V. Reliable estimation of the kinetic parameters of redox enzymes by taking into account mass transport towards rotating electrodes in protein film voltammetry experiments. Electrochim. Acta 245, 1059-1064 (2017).

51. Burroughs, A. M., Balaji, S., Iyer, L. M. \& Aravind, L. A novel superfamily containing the beta-grasp fold involved in binding diverse soluble ligands. Biol. direct 2, 4 (2007).

\section{Acknowledgements}

We thank the staff at beamline ID29 (ESRF, Grenoble) for technical support during X-ray data collection. M.W., J.D., and T.H. gratefully acknowledge financial support from the Volkswagen-Stiftung (Design of [FeS]-cluster containing Metallo-DNAzymes (Az 93412)), from the Deutsche Forschungsgemeinschaft (DFG, German Research Foundation) under Germany's Excellence Strategy - EXC 2033 - Project number 390677874 and the DIP Programme (LU 315/17-1). T.H. and E.H. also received funding within the DFG Research Training Group GRK 2341: (Microbial Substrate Conversion). The French authors are supported by the CNRS, Aix Marseille Université, Agence Nationale de la Recherche and the Excellence Initiative of Aix-Marseille University - A*MIDEX, a French "Investissements d'Avenir" programme (ANR-12-BS08-0014, ANR-14-CE050010, ANR-11-IDEX-0001-02). The Italian authors are supported by University of Torino funding RICERCA LOCALE and wish to acknowledge the DAAD program for supporting collaboration with the Department of Plant Biochemistry, Ruhr-Universität Bochum and Erasmus traineeship for collaboration with CNRS.

\section{Author contributions}

T.H., M.W. and C.L. conceived and supervised the project, which was initiated during a collaboration with G.G and F.V. about the structure of CbA5H. C.L., C.F. and V.F. were responsible for recording cyclic voltammetries of the protein and kinetic modeling. A.R. crystallized the protein and J.D. and E.H. solved the structure. J.D., M.W. and E.H. 
performed structural analysis. M.W. and J.D. designed the mutagenesis variants. L.S. and J. J. purified the protein and measured the activity. M.W., O.L., J.J. and J.D. carried out the chronoamperometry experiment. A.R. and L.S. performed the ATR-FTIR experiments. U.P.A. synthetized the $[2 \mathrm{Fe}]_{\mathrm{H}}$ complex for in vitro maturation. M.W., C.L., T.H., J.D. and C.F. wrote the manuscript with input from other coauthors. All authors discussed and commented on the manuscript.

\section{Competing interests}

The authors declare no competing interests.

\section{Additional information}

The online version contains supplementary material available at https://doi.org/10.1038/ s41467-020-20861-2.

Correspondence and requests for materials should be addressed to C.L. or T.H.

Peer review information Nature Communications thanks Christopher Pickett, Stephen Carr, and the other anonymous reviewers for their contribution to the peer review of this work. Peer reviewer reports are available.
Reprints and permission information is available at http://www.nature.com/reprints

Publisher's note Springer Nature remains neutral with regard to jurisdictional claims in published maps and institutional affiliations.

(c) (i) Open Access This article is licensed under a Creative Commons Attribution 4.0 International License, which permits use, sharing, adaptation, distribution and reproduction in any medium or format, as long as you give appropriate credit to the original author(s) and the source, provide a link to the Creative Commons license, and indicate if changes were made. The images or other third party material in this article are included in the article's Creative Commons license, unless indicated otherwise in a credit line to the material. If material is not included in the article's Creative Commons license and your intended use is not permitted by statutory regulation or exceeds the permitted use, you will need to obtain permission directly from the copyright holder. To view a copy of this license, visit http://creativecommons.org/ licenses/by/4.0/.

(C) The Author(s) 2021 